\title{
SOURCE CHARACTERISTICS OF SHALLOW EARTHQUAKES IN THE NORTHERN PART OF SANRIKU-OKI REGION, JAPAN
}

\author{
Yasuo IzUTANi* and Tomowo HiRASAwA** \\ * Department of Civil Engineering, Faculty of Engineering, \\ Shinshu University, Nagano, Japan \\ **:Observation Center for Earthquake Prediction, Faculty of Science, \\ Tôhoku University, Sendai, Japan
}

(Received March 22, 1978)

\begin{abstract}
Six shallow earthquakes, which occurred in the Sanriku-Oki region during the period from 1965 to 1970 , are studied by using long-period Pand S-waves. Focal mechanism solutions are determined from the S-wave polarization angles. Fault planes, which are distinguished from the auxiliary planes by means of the hypocenter distribution of aftershocks, are slightly dipping toward the island arc. A linear correlation is found between the dip angle of fault plane and the distance of epicenter from the trench axis; the dip angle increases with increasing distance. The motion directions of the foot wall blocks relative to the hanging wall sides are in the range from $\mathrm{N} 58^{\circ} \mathrm{W}$ to $\mathrm{N} 72^{\circ} \mathrm{W}$ and are consistent with the expectation from the plate tectonics theory, the motion direction of the Pacific plate relative to the Eurasia plate. The focal depths re-determined by the use of depth phases such as $\mathrm{PP}$ and $\mathrm{sP}$ reveal that the hypocenters of the six earthquakes lie almost on a plane slightly dipping toward the island arc.

The spectral analysis of $\mathrm{P}$-waves is made to elucidate the dynamic source process. To do this, the effects of multiple reflection in the crust near the source region as well as beneath the station are taken into account. A unilateral bidirectional model of faulting appropriate to each event is determined by comparing the trough frequencies in the observed P-wave spectra with those expected theoretically. The fracture is found to have propagated in the motion direction of the foot wall block with a velocity between 2.0 and $3.1 \mathrm{~km} / \mathrm{sec}$.
\end{abstract}

\section{Introduction}

The so-called finite moving source model has been applied to elucidate the source process of earthquakes. For example, Hrrasawa (1965) distinguished a particular phase from other phases in the $P$-wave trains from the Niigata earthquake of 1964 in comparison with the wave-forms from its after- 
shock. Identifying the phase as a stopping phase, he determined the fault length and the rupture velocity for the main shock from the arrival time differences between the initial phases and stopping phases. BoLlinger (1968, 1970), Mikumo (1969, 1971), and Fukao (1970) derived the source processes from the azimuthal effect of the propagating fault on the pulse widths of radiated body waves. KHATTRI (1969) paid attention to the existence of troughs in the amplitude spectra of P-waves radiated from a large deep earthquake. Regarding these troughs as the effect of interference between the initial phase and the stopping phase, he obtained the source dimension and the rupture velocity by using the unilateral bidirectional faulting model presented by Hirasawa and Stauder (1965).

Up to now, many earthquakes have been analyzed by methods similar to those mentioned above primarily to understand the faulting mechanism of individual earthquakes. This paper aims at a comparative study of source processes of earthquakes occurring in a particular region of importance from the viewpoint of the plate tectonics theory, to reveal the similarity and dissimilarity in faulting process of earthquakes, and to have a better understanding of the characteristics of earthquake generating mechanism in the tectonic region. Our study will be made for the northern part of the Sanriku-Oki region, the subduction zone of the Pacific plate beneath the northeastern Japan arc. In this region the Tokachi-Oki earthquake of 1968 occurred and the tectonical complexity was found by KANAMORI (1971) through the analysis of surface waves radiated from the earthquake and its two aftershocks. We attempt to study the source mechanism of six shallow earthquakes which occurred prior to or after the Tokachi-Oki earthquake in this region.

\section{Data Analyzed}

The six earthquakes analyzed in this study occurred in the Sanriku-Oki region. Their origin times, hypocentral coordinates and magnitudes are given by the Japan Meteorological Agency (JMA) and the U.S. Coast and Geodetic Survey (USCGS) as shown in Table 1 and in Fig. 1. The differences between the epicentral coordinates by JMA and those by USCGS are not so significant for our analysis, because the observation stations concerned are sufficiently far from the focal region. The epicentral coordinates by USCGS are adopted in this study. On the other hand, the uncertainty of the focal depths of the earthquakes severely affects the source model that we shall construct to investigate the source process. The focal depths will be re-determined in section 7 .

Observation stations of the World Wide Standard Seismograph Network (WWSSN) are so chosen for our analysis that their distribution may cover 
Table 1. Earthquake data.

Event
$\begin{array}{cc}\text { Date } \\ 1 & \text { Mar. 16, 1965 } \\ 2 & \text { Mar. 29, 1965 } \\ 3 & \text { May 16, 1968 } \\ 4 & \text { May 22, 1968 } \\ 5 & \text { Nov. 11, 1968 } \\ 6 & \text { May 27, 1970 }\end{array}$

(by U.S.C.G.S.)

$\begin{array}{cc}\text { Event } & \text { Date } \\ 1 & \text { Mar. 16, 1965 } \\ 2 & \text { Mar. 29, 1965 } \\ 3 & \text { May 16, 1968 } \\ 4 & \text { May 22, 1968 } \\ 5 & \text { Nov. 11, 1968 } \\ 6 & \text { May 27, 1970 }\end{array}$

(by J.M.A.)

\begin{tabular}{ccccc} 
Origin time & $\begin{array}{c}\text { Latitude } \\
(\mathrm{N})\end{array}$ & $\begin{array}{c}\text { Longitude } \\
(\mathrm{E})\end{array}$ & Depth & Magnitude \\
\hline $6^{4} 46^{\mathrm{m}} 15.5^{5}$ & $40.8^{\circ}$ & $142.9^{\circ}$ & $34^{\mathrm{k} m}$ & 5.6 \\
104737.6 & 40.8 & 142.8 & 33 & 6.1 \\
230454.7 & 39.8 & 143.1 & 37 & 5.8 \\
192925.7 & 40.2 & 142.3 & 40 & 5.3 \\
144115.9 & 40.1 & 143.0 & 35 & 5.5 \\
190539.0 & 40.3 & 143.0 & 33 & 5.7
\end{tabular}

\begin{tabular}{|c|c|c|c|c|}
\hline Origin time & $\begin{array}{l}\text { Latitude } \\
\qquad(\mathrm{N})\end{array}$ & $\begin{array}{l}\text { Longitude } \\
\text { (E) }\end{array}$ & Depth & Magnitude \\
\hline $16^{\mathrm{m}} 46^{\mathrm{m}} 13.7^{\mathrm{s}}$ & $40.70^{\circ}$ & $143.20^{\circ}$ & $40^{\mathrm{km}}$ & 6.4 \\
\hline $1047 \quad 35.7$ & 40.65 & 143.15 & 40 & 6.4 \\
\hline 230450.6 & 39.77 & 143.48 & 30 & 6.7 \\
\hline 192924.0 & 40.25 & 142.57 & 30 & 6.3 \\
\hline $1441 \quad 12.5$ & 40.12 & 143.42 & 30 & 6.0 \\
\hline $\begin{array}{lll}19 & 05 & 35.3\end{array}$ & 40.15 & 143.25 & 30 & 6.2 \\
\hline
\end{tabular}

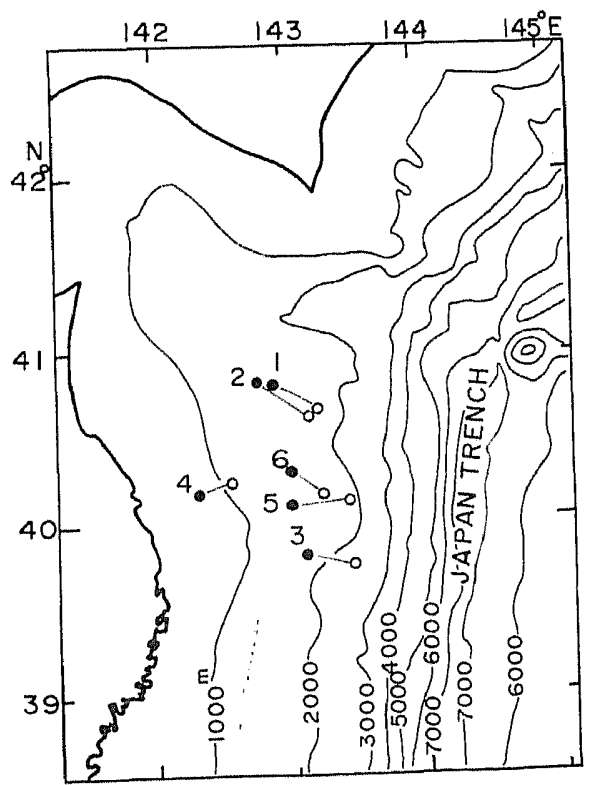

Fig. 1. Epicenters of six events. Solid and open circles indicate the epicenters determined by USCGS and by JMA, respectively. Contours denote the water depth.

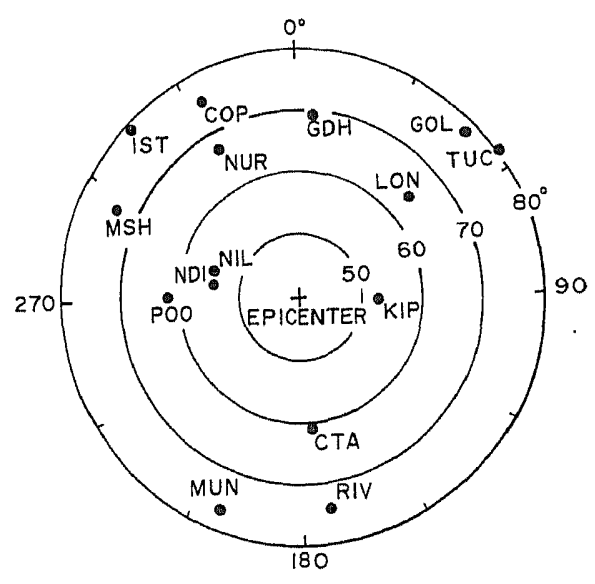

Fig. 2. Approximate station locations relative to the epicentral region of six events. Concentric circles show epicentral distances. 
all the azimuths from the focal region, and that their epicentral distance ranges from $50^{\circ}$ to $80^{\circ}$. They are also required to have recorded all the earthquakes in order that the seismograms at the same station may be analyzed. The azimuths and the epicentral distances are shown in Fig. 2.

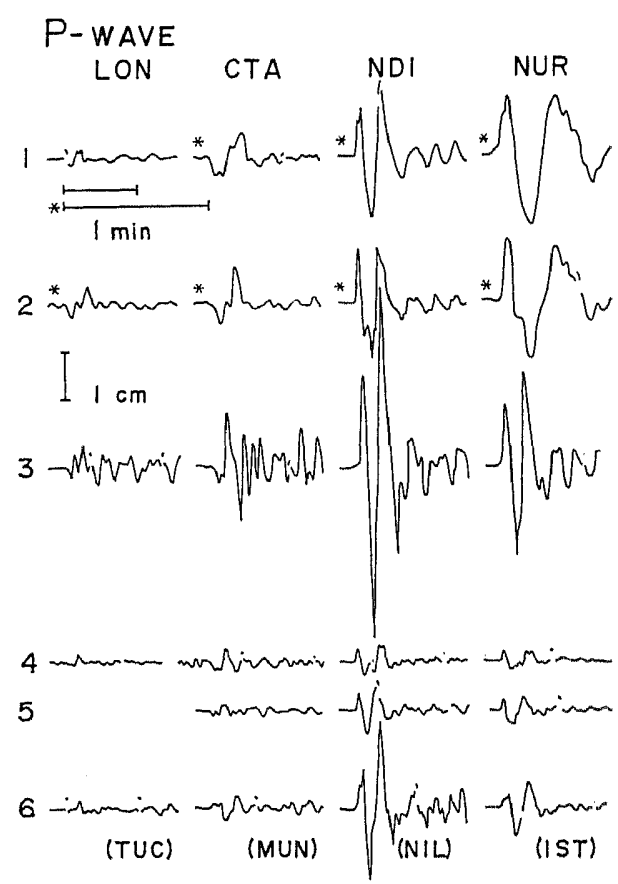

Fig. 3. Examples of the P-waves for six events in vertical component. Time scale marked by asterisk should be applied to the seismograms with asterisk.

Table 2. Instrumental constants.

\begin{tabular}{ccccc}
\hline Station & $T_{0}(\mathrm{sec})$ & $T_{\mathrm{g}}(\mathrm{sec})$ & $m$ & \\
\hline L ON & 30 & 100 & 1,500 & for events 1 and 2 \\
& 15 & 100 & 1,500 & 3 and 4 \\
C T A & 30 & 100 & 3,000 & 1 and 2 \\
& 15 & 100 & 3,000 & 3,4 and 5 \\
ND I & 30 & 100 & 1,500 & 1 and 2 \\
& 15 & 99 & 1,500 & 3,4 and 5 \\
NUR & 30 & 100 & 3,000 & 1 and 2 \\
& 15 & 100 & 1,500 & 3,4 and 5 \\
TUC & 15 & 100 & 1,500 & 6 \\
MUN & 15 & 100 & 1,500 & 6 \\
N I L & 15 & 100 & 1,500 & 6 \\
I S T & 15 & 100 & 1,500 & 6
\end{tabular}

$T_{0}$, Seismometer period; $T_{\mathrm{g}}$, Galvanometer period; $m$, Magnification. 
Some examples of $\mathrm{P}$-waves in the vertical component are exhibited in Fig. 3. The seismometer period, the galvanometer period and the magnification of the instrument used are listed in Table 2.

\section{Focal Mechanism Solution}

The focal mechanism solutions of the six earthquakes are determined from the polarization angles of S-waves by the use of the computer program by HIRASAWA (1966). The observed polarization angles are illustrated by arrows in Fig. 4, where the lower half of the focal sphere is projected on an equal area net. Solid and open circles in the figure indicate dilatations and compressions of $\mathrm{P}$-wave first motions, respectively, and small crosses ambiguous readings. The obtained solutions are considered to be reliable because of the small standard deviations shown in Table 3 and of the satisfactory agreement with the observations of $\mathrm{P}$-wave initial motions. The mechanism solutions of events 2 and 3 are similar to those previously obtained by SASATANI (1973) and KANAMORI (1971), respectively.

In order to examine the reliability of these mechanism solutions more critically, we plot in Fig. 5 the observed amplitudes of P-wave initial motions recorded on seismograms of vertical component versus the theoretical amplitudes of P-wave radiation expected for the obtained solution at individual stations. The observed amplitudes are assumed to be zero for stations where the initial motion directions of P-waves are ambiguous. Here, the observed amplitudes have been corrected for the geometrical spreading, the attenuation

Table 3. Focal mechanism solution.

\begin{tabular}{|c|c|c|c|c|c|c|c|}
\hline \multirow{2}{*}{ Event } & \multicolumn{3}{|c|}{ Plane a } & \multicolumn{3}{|c|}{ Plane $b$} & \multirow{2}{*}{$\sigma$} \\
\hline & si & $a$ & $\lambda$ & $\psi$ & $\delta$ & $\lambda$ & \\
\hline 1 & $\begin{array}{r}88.216 \\
(22.180)\end{array}$ & $\begin{array}{l}18.223 \\
(2.636)\end{array}$ & $\begin{array}{l}105.525^{\prime} \\
(19.068)\end{array}$ & $\begin{array}{r}108.087^{\circ} \\
(5.717)\end{array}$ & $\begin{array}{l}72.464^{\circ} \\
(1.287)\end{array}$ & $\begin{array}{l}84.964^{\circ} \\
(6.703)\end{array}$ & $13.538^{\circ}$ \\
\hline 2 & $\begin{array}{l}23.160 \\
(15.734)\end{array}$ & $\begin{array}{l}17.716 \\
(2.177)\end{array}$ & $\begin{array}{c}51.606 \\
(15.256)\end{array}$ & $\begin{array}{c}117.083 \\
(3.165)\end{array}$ & $\begin{array}{l}76.202 \\
(1.638)\end{array}$ & $\begin{array}{c}101.222 \\
(5.004)\end{array}$ & 6.603 \\
\hline 3 & $\begin{array}{c}52.780 \\
(15.082)\end{array}$ & $\begin{array}{l}14.120 \\
(0.710)\end{array}$ & $\begin{array}{c}84.933 \\
(11.380)\end{array}$ & $\begin{array}{c}121.996 \\
(3.649)\end{array}$ & $\begin{array}{l}75.937 \\
(0.550)\end{array}$ & $\begin{array}{l}91.273 \\
(2.899)\end{array}$ & 12.700 \\
\hline 4 & $\begin{array}{r}55.336 \\
(9.613)\end{array}$ & $\begin{array}{l}23.568 \\
(1.129)\end{array}$ & $\begin{array}{l}76.687 \\
(5.288)\end{array}$ & $\begin{array}{c}110.188 \\
(4.639)\end{array}$ & $\begin{array}{l}67.102 \\
(1.135)\end{array}$ & $\begin{array}{l}75.736 \\
(2.292)\end{array}$ & 7.952 \\
\hline 5 & $\begin{array}{c}51.144 \\
(15.075)\end{array}$ & $\begin{array}{l}14.470 \\
(0.859)\end{array}$ & $\begin{array}{c}82.581 \\
(11.160)\end{array}$ & $\begin{array}{l}121.196 \\
(3.885)\end{array}$ & $\begin{array}{l}75.654 \\
(0.601)\end{array}$ & $\begin{array}{l}91.908 \\
(2.947)\end{array}$ & 8.763 \\
\hline 6 & $\begin{array}{r}-75.960 \\
(20.625)\end{array}$ & $\begin{array}{l}16.112 \\
(1.197)\end{array}$ & $\begin{array}{l}102.868 \\
(16.271)\end{array}$ & $\begin{array}{l}117.416 \\
(5.403)\end{array}$ & $\begin{array}{l}74.303 \\
(0.995)\end{array}$ & $\begin{array}{l}86.319 \\
(4.741)\end{array}$ & 10.923 \\
\hline
\end{tabular}

4 . Dip direction; $i$, Dip angle; $\lambda$, Slip angle; $\sigma$, Standard deviation of polarization angle; ( ), Standard deviation of the corresponding quantity. 

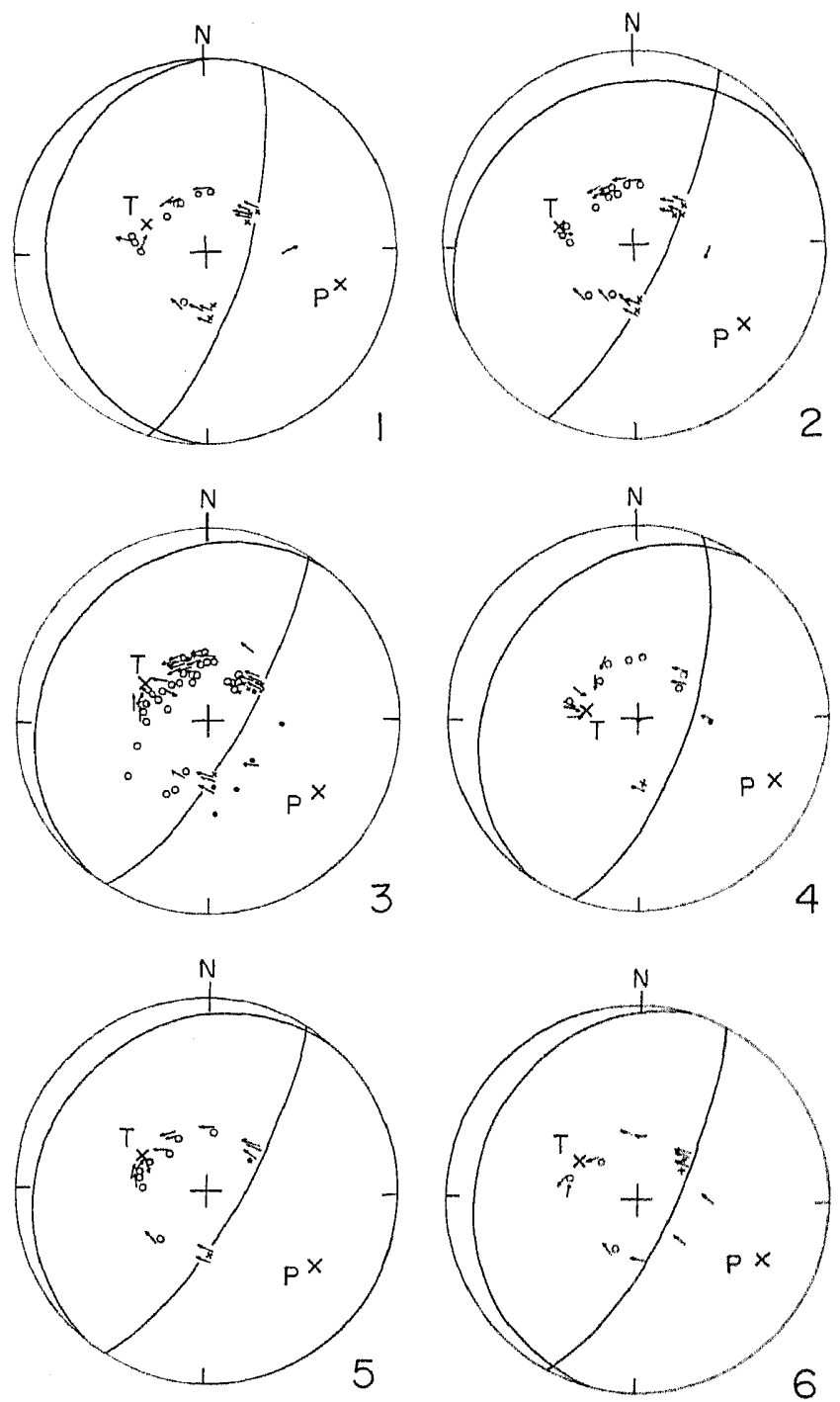

Fig. 4. Radiation patterns of the observed P-and S-waves for events from 1 to 6. The lower half of focal sphere is projected on the equal area net. Open and solid circles are compressions and rarefactions, respectively. Ambiguous first motions are denoted by small crosses. Solid curves indicate the $\mathrm{P}^{\mathrm{P}}$-nodal planes obtained from the polarization angles of S-waves by the use of the least squares method. Number of observations used for focal mechanism determination are 15 (event 1), 19 (event 2), 31 (event 3), 10 (event 4), 14 (event 5), and 12 (event 6 ).

of the wave energy due to anelasticity in the mantle, and for the magnification of the seismograph. For the geometrical spreading the distance factor, $f$, was given by HoNDA (1962) as follows; 

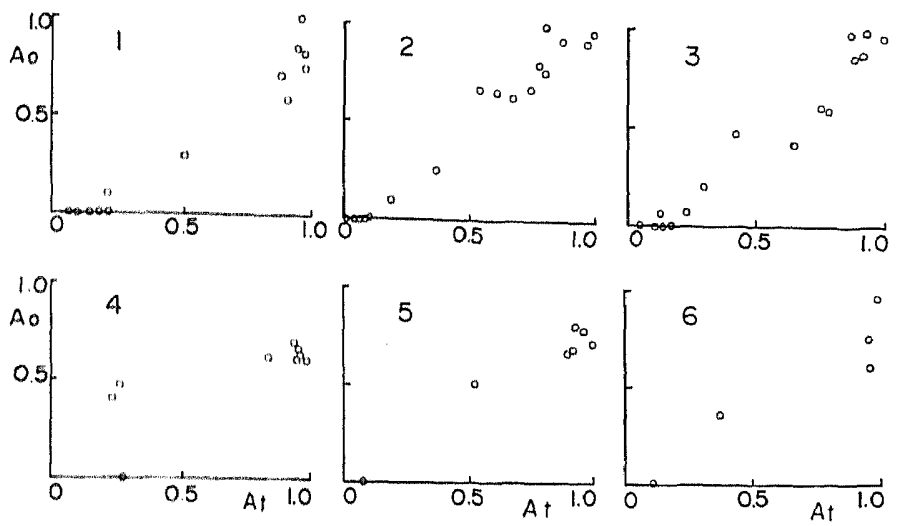

Fig. 5. Correlation between the observed amplitudes of P-waves and those theoretically expected from the least squares solution for each event.

$$
f=\frac{1}{R} \sqrt{\rho_{11} v_{\mathrm{h}}} \sqrt{\sin i_{\mathrm{n}}} v_{0} v_{\sin \Delta \cos i_{0}}\left|\begin{array}{l}
\mathrm{d} i_{\mathrm{h}} \\
\mathrm{d} \Delta
\end{array}\right|,
$$

where $R, \rho, v$ and $i$ are the radius of the earth, the density, the wave velocity, and the angle of incidence, respectively. The subscript 0 or $\mathrm{h}$ stands, respectively, for the quantity at the earth's surface or at the hypocenter, and $\Delta$ is the epicentral distance in degree. The attenuation is approximately expressed by Bri-MENAHEM et al. (1965) as

$$
H_{\mathrm{M}}(\omega)=\exp \left\{-(\omega \tau) / 2 Q_{0}\right\} ; \quad \omega=\frac{2 \pi}{T},
$$

where : is the travel time and $T$ the period of the wave. For the present discussion $T$ is assumed to be $10 \mathrm{sec}$, corresponding to the dominant period of P-waves. $Q_{0}$ is the average value of $Q$ along the ray path, and here assumed to be 400 for P-waves. Since the seismograph is standardized, the correction of the seismograph response may not be necessary for the relative comparison, except for the difference in the maximum magnification. The effect of the crustal layering is not removed, since the amplitude response of the crustal layering around $10 \mathrm{sec}$ varies little with respect to incident angle at the stations in the epicentral distance range concerned.

The unit of the ordinate in Fig. 5 is taken arbitrarily, but the relative comparisons of amplitude are possible among the stations. A linear correlation between theory and observation is obvious in this figure for each event, though the agreement is relatively poor for event 4 . It follows from this that the solutions obtained independently of P-wave observations satisfactorily explain the amplitude pattern of P-waves.

The focal mechanism solutions of the six earthquakes are all of the 
thrust-faulting type and have nodal planes with nearly the same dip direction and dip angle, except for slight differences in dip angle for event 4 and in dip direction for event 2 . This type of focal mechanism solution is often found for shallow earthquakes not only in this region but also in almost all the island arcs under the inner margin of the trench (e.g. STAUDER, 1968; IsACKs et al., 1968).

\section{Determination of Fault Plane}

In order to distinguish the fault plane from the auxiliary plane the hypocenter disribution of aftershocks is examined under the assumption that aftershocks occur at points near the fault surface of the main shock. Here the term main shock means the individual event from 1 to 6 and aftershock means earthquakes that occurred near the hypocenter of the main shock within a few days after the main shock.

The intervals between the arrival times of P-waves from aftershocks and that from the main shock for each observation station are obtained from the Bulletins of International Seismological Center (ISC). If the absolute value of O-C time given in the bulletin is greater than $5.0 \mathrm{sec}$, the use of the station is avoided. We also omit any station whose initial phase is a diffracted wave or PKP wave. The computer program by Kusunose and Hrrasawa (1977) is used to determine the hypocenter of aftershock relative to that of main shock. The results for individual events are illustrated on the focal sphere together with the nodal planes in Fig. 6. As the lower half of the focal sphere
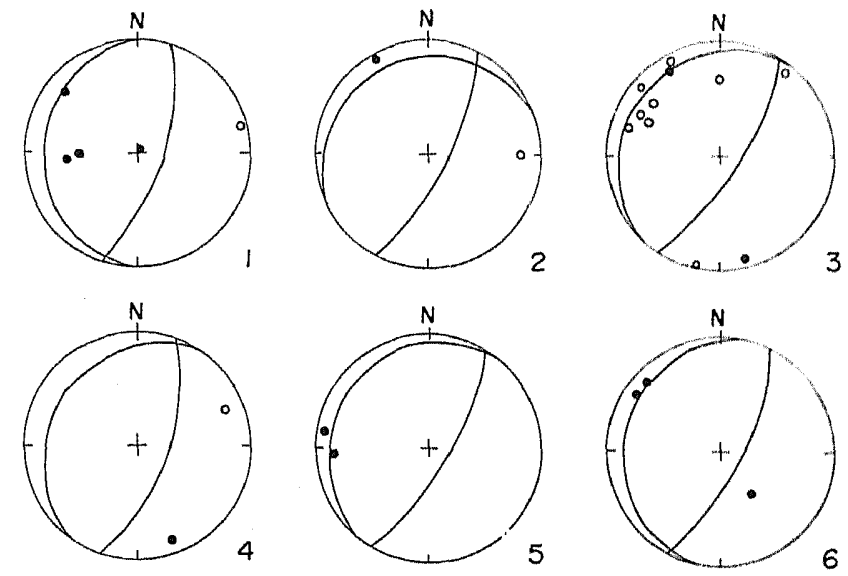

Fig. 6. Locations of aftershocks relative to the hypocenter of each event, projected on the lower half of the focal sphere, together with the P-nodal planes. Open and solid circles indicate the projected point of aftershocks shallower and deeper than the main event, respectively. 
is projected on an equal area net, the hypocenters of aftershocks shallower than that of the main shock are transferred from the upper half to the symmetrical points on the lower half of the focal sphere. Open and solid circles indicate the projected points of the hypocenters of aftershocks shallower and deeper than the main shock, respectively.

From this result it seems that except for a few cases the aftershocks are in a cluster near one of the nodal planes which is slightly dipping toward the island are. In event 4 , the fault plane will be distinguished from another viewpoint in section 8 . Thus, we conclude that these planes are the fault planes. The azimuths of motion directions of foot wall blocks against the hanging wall sides are all in the range from $-58^{\circ}$ to $-72^{\circ}$. This result is consistent with the expectation from the plate tectonics theory, that is, the underthrusting motion of the Pacific plate beneath the northeastern Japan arc.

\section{Some Re'marks on Fourier Spectra}

Seismograms of P-waves in the vertical component are digitized and transformed into the frequency domain by the fast Fourier transform algolism. The sampling interval is taken to be $1.33 \mathrm{sec}$, that is, 45 samples per minute. We use the hanning window (BLACKMAN and TUKEY, 1958). The center of the data window is placed at the onset of the P-waves, and the half width of the window is taken to be 45 sec.

According to TENG and BEN-MENAInEM (1965) the instrumental response of seismograph at a station of WWSSN is expressed by

$$
\begin{aligned}
& H_{l}((\omega))=\frac{m \omega^{3}\left(\omega_{0}\right)}{\left(\omega_{0}{ }^{2}+\left(\omega^{2}\right)\left(\omega_{k}{ }^{2}+\left(\omega^{2}\right)\right.\right.}{ }^{2}, \\
& \left(D_{1}(\omega)\right)=\frac{1}{\pi}\left(\tan ^{-1}{ }^{(1)}(\omega)+\tan ^{-1} \frac{()_{k}}{(1)}\right)-\frac{1}{4}, \\
& (1)_{11}=\begin{array}{l}
2 \pi \\
T_{0}
\end{array}, \quad()_{k}=\begin{array}{l}
2 \pi \\
T_{k n}
\end{array},
\end{aligned}
$$

where $T_{4}$ and $T_{R}$ are the pendulum and galvanometer periods, and $m$ is a normalization constant appropriate to the magnification of an individual instrument.

The observed spectra for the six events are exhibited in azimuthal order in Fig. 7, where the ordinates are arbitrarily taken. Since additional corrections the crustal response, the attenuation due to anelasticity of the mantle and the geometrical spreading - have not yet been made, the spectra are those of the ground displacement at the stations.

A series of troughs can be seen in the spectra. KHATtRI (1969) paid 

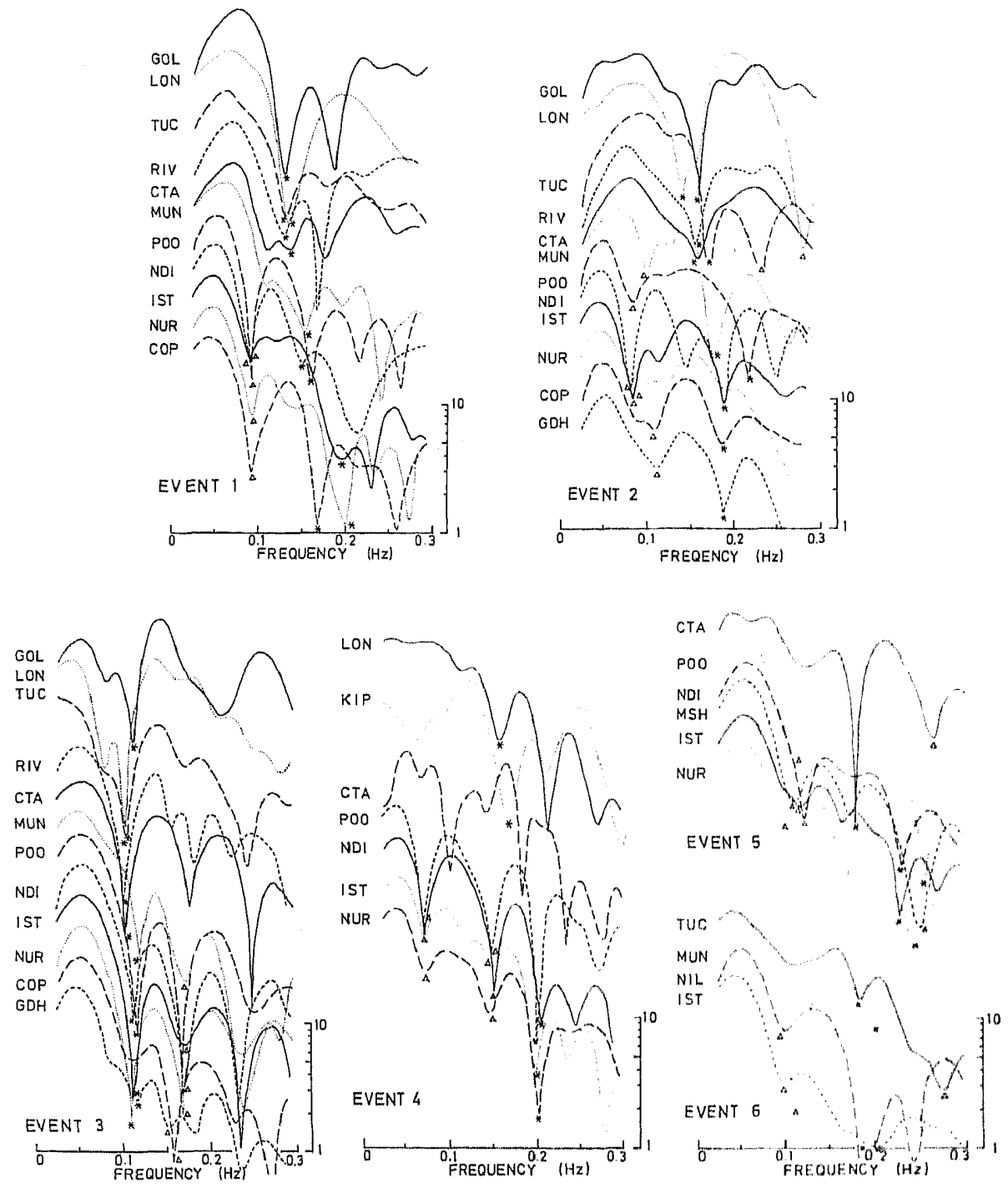

Fig. 7. Displacement spectra of the observed P-waves. They are exhibited in the azimuthal order for the purpose of comparison of their shapes. The unit of amplitude is arbitrary. Spectral troughs marked by asterisk or by triangle are those caused by the effect of the source finiteness or by the interference of reflected waves, respectively, as discussed in sections 7 and 8 .

attention to the first troughs in P-wave spectra from a deep earthquake and regarded them as those due to the effect of source finiteness. Since the earthquake analyzed in his study is deep enough, the $\mathrm{P}$-waves are isolated from $\mathrm{pP}$ - and sP-waves. In the present study, however, the earthquakes are shallow 
and the $\mathrm{pP}$ - and sP-waves follow the direct $\mathrm{P}$-waves with a time lag of about $10 \mathrm{sec}$. Therefore, the contribution of reflected waves to the observed spectra must first be eliminated to detect the azimuthal effect due to source finiteness.

\section{Theoretical Preparation}

As the source model for the six events, we assumed the theoretical source model of unilateral bidirectional faulting after HIRAsAWA and STAUder (1965). A double couple of body forces and the fault geometry are shown in Fig. 8. The $z$-axis on the fault plane expresses the motion direction of the foot wall block relative to the hanging wall side. $a$ and $b$ are the fault lengths along the $\xi$ - and $\eta$-axes, respectively. The fracture front which is assumed to be expressed by a straight line propagates with a constant rupture velocity, $v_{n}$, from the origin of the coordinate $\operatorname{system}(\xi, \eta, \zeta)$. The apparent rupture velocities $v_{a}$ and $v_{b}$ along the $\xi_{-}$and $\gamma_{\text {-axes, }}$ respectively, are given as

$$
\begin{aligned}
& v_{a}=v_{\mathrm{R}} / \cos \gamma, \\
& v_{b}=v_{\mathrm{R}} / \sin \gamma,
\end{aligned}
$$

where $\gamma$ is the angle measured clockwise from the $\xi$-axis to the propagation direction of the fracture front.

According to Hirasawa and Stauder (1965), the displacement $U_{\mathrm{p}}$ for $P$-waves at a far field is

$$
\begin{aligned}
& U_{\mathrm{p}}=\underset{4 \pi \rho v_{1 ;} ;}{K} \cdot \frac{1}{r_{0}} \cdot R(\Theta, \Phi) \cdot \frac{1}{2 \pi} \int_{-\infty}^{\infty} I_{\mathrm{p}} \mathrm{e}^{i \omega t} \mathrm{~d}(\omega), \\
& I_{1}=a \cdot b \cdot \dot{H}(\omega) \cdot \underset{\omega(1) X_{\mathrm{p}}}{\sin \omega X_{\mathrm{p}}} \cdot \frac{\sin \omega Y_{1}}{\omega} Y_{\mathrm{p}} \cdot \exp \left\{-i \omega\left(\frac{r_{0}}{v_{\mathrm{p}}}+X_{\mathrm{p}}+Y_{\mathrm{p}}\right)\right\} \text {, } \\
& X_{1}=a_{2}^{a}\left(\begin{array}{cc}
1 & r_{\xi} \\
v_{a} & v_{1}
\end{array}\right), \quad Y_{1}=\frac{b}{2}\left(\frac{1}{v_{b}}-\frac{\gamma_{\eta}}{v_{\mathrm{p}}}\right), \\
& \dot{F}(\omega)=\int_{-\infty}^{\infty} \frac{\mathrm{d} f(t)}{\mathrm{d} t} \mathrm{e}^{-i \omega t} \mathrm{~d} t
\end{aligned}
$$

where $v_{\mathrm{r}}$, is the P-wave velocity, $\rho$ is the density, $K$ is the magnitude of the body force, $R(\Theta, \Phi)$ represents the radiation pattern, $f(t)$ is a time function of displacement discontinuity, and $\gamma_{\xi}$ and $\gamma_{\eta}$ are the direction cosines between the ray toward the station and the $\xi$-and $\eta$-axes, respectively.

These expressions are, however, unsatisfactory for shallow earthquakes. It is considered that the effect of multiply reflected waves in the crust near the source region may play an important role in the observed displacements of body waves. Assuming a uni-layered crust model, the effect of multiply reflected waves, which leave the bottom of the crust with the same angle of 

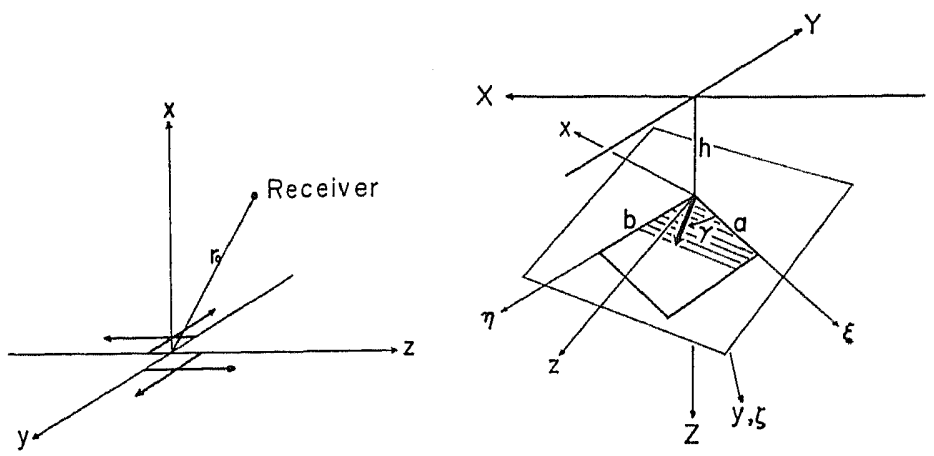

Fig. 8. A double couple of body forces and the geometry of bidirectional model. The $x-, z-, \xi-$ and $\eta$-axes lie on the fault plane. The motion direction of the foot wall block is in the direction of $z$-axis. Line segments on the fault denote the rupture front propagating in the direction of thick arrow.

incidence as that of the direct $\mathrm{P}$-wave and propagate into the mantle as Pwaves, is taken into account by replacing $I_{\mathrm{f}}$ in (5) by the following expression,

$$
\begin{aligned}
I(\omega)= & \sum_{i=1}^{4}\left[\left(\frac{v_{\mathrm{p}}}{v_{i}}\right)^{3} C_{i} \cdot a \cdot b \cdot \dot{F}(\omega) \cdot \frac{\sin \omega X_{i}}{\omega X_{i}} \cdot \frac{\sin \omega Y_{i}}{\omega Y_{i}}\right. \\
& \left.\times \exp \left\{-i \omega\left(\frac{r_{0}}{v_{\mathrm{p}}}+X_{i}+Y_{i}\right)\right\} \sum_{j=1}^{n} D_{i j} \exp \left(-i \phi_{i j}\right)\right], \\
X_{i}= & \frac{a}{2}\left(\frac{1}{v_{a}}-\frac{\delta_{\xi i}}{v_{i}}\right), \quad Y_{i}=\frac{b}{2}\left(\frac{1}{v_{b}}-\frac{\gamma_{\eta i}}{v_{i}}\right),
\end{aligned}
$$

where the subscript $i$ discriminates four types of original waves radiated from the source as;

$i=1$; for waves radiated downward as P-waves,

2; for waves radiated upward as P-waves,

3; for waves radiated upward as SV-waves,

4; for waves radiated downward as SV-waves.

Accordingly, $v_{1}$ and $v_{2}$ are identical with $v_{p}$, and $v_{3}$ and $v_{4}$ with $v_{s}$. In the above expressions, $n$ represents the number of the reflected waves considered, $C_{i}$ the radiation pattern of the $i$-th reflected wave normalized by that of the direct P-waves, $D_{i j}$ is the product of the reflection and/or transmission coefficients at the earth's surface or at the Moho, and $\phi_{i j}$ is the factor of phase delay due to the difference of the ray path relative to the direct $\mathbf{P}$-waves. If the source is beneath the Moho, the terms having $i=4$ are not necessary. For practical purposes, it is assumed that the multiple reflection of body waves in the crust can be treated by the reflection theory of the plane waves in order to evaluate $D_{i j}$ and $\phi_{i j}$ approximately. $I(\omega)$ in $(6)$ is calculated only 
for the waves arriving at the station within $60 \mathrm{sec}$ after the arrival of direct P-waves.

The attenuation, $H_{M}(\omega)$, due to anelasticity in the mantle is calculated from (2) by assuming $Q_{0}$ to be 400 for P-waves. For the crustal response, $H_{C R}((1))$, beneath a station, the same method of the multiple reflection as that for the source region is used. Assuming that the mantle and the crust are linear systems, the spectrum of the ground displacement at a station is expressed as

$$
\Gamma(\omega)=\underset{4 \pi \rho v_{\mathrm{n}}{ }^{3}}{K} \cdot \frac{1}{r_{0}} \cdot R(\Theta, \Phi) \cdot I(\omega) \cdot H_{\mathrm{M}}(\omega) \cdot H_{\mathrm{CR}}(\omega)
$$

In addition, using the instrumental response of the seismograph given by (3), the displacement expected to be recorded by a seismograph of vertical component is expressed as

$$
U_{\mathrm{I}}=\frac{1}{2 \pi} \int_{-\infty}^{\infty} \Gamma(\omega) \cdot H_{\mathrm{I}}(\omega) \cdot \exp \left\{i\left(\omega t+\Phi_{\mathrm{I}}(\omega)\right\} \mathrm{d} \omega .\right.
$$

The expression for SH-waves can also be obtained through the same procedure, where $Q_{0}=200$ is assumed.

\section{Re-Determination of Focal Depth}

In order to separate the effect of reflected waves on the P-wave spectra from that of source finiteness, at first we compute the theoretical spectrum for each station by using the focal mechanism solution obtained previously for each event. The uni-layered crust model used by Haskell (1960) is adopted for the sake of simplicity. The thickness of the crust is assumed to be $25 \mathrm{~km}$ for the focal region and $37 \mathrm{~km}$ for all the stations.

Impulsive waveforms are assumed for $\mathrm{P}$ - and $\mathrm{S}$-waves radiated from the source. The theoretical spectrum thus obtained includes depth phases, such as $\mathrm{PP}, \mathrm{sP}$ and multiply reflected waves in the crust near both the source and the station. Moreover, the effect of the anelastic attenuation in the mantle being taken into consideration, the comparison of spectral structure is possible between the theoretical spectrum and the observed one.

As an example, the theoretical spectra of event 2 for the focal depth of $30 \mathrm{~km}$, which is the best value for the observation among several values of the depth, are compared with the observed ones in Fig. 9. Sharp troughs can be seen in the theoretical spectra for LON and CTA at the frequency $1 / \tau$ (about $0.26 \mathrm{~Hz}$ ), where $\tau$ is equal to sP-pP time. On the other hand, a series of troughs appear in the theoretical spectra for NDI and NUR at frequencies $n / \tau^{\prime}$ (about $0.08,0.16$ and $0.24 \mathrm{~Hz}$ ), where $\tau^{\prime}$ is equal to sP-P time and $n$ are integers. These phenomena may easily be understood by taking into account 
the focal mechanism solution, that is, the amplitudes of P-waves for LON and CTA and those of PP waves for NDI and NUR are so small that their effects on the spectra may disappear.

If we assume on trial that the first troughs observed at LON and CTA (at about $0.15 \mathrm{~Hz}$ ) are due to the effect of interference between $\mathrm{pP}$ - and SPwaves, the focal depth should be about $55 \mathrm{~km}$. However, the focal depth of $55 \mathrm{~km}$ cannot be adopted, because, if so, the theoretical troughs at NDI and NUR would appear at a frequency of about $0.05 \mathrm{~Hz}$, where no troughs can be seen in the observed spectra. It is thus concluded that the observed first troughs at LON and CTA should be regarded as those due to the effect of source finiteness. On the other hand, if we try to explain the observed first troughs at NDI and NUR (at about $0.08 \mathrm{~Hz}$ ) as being due to the effect of source finiteness, the pulse widths of waves radiated from the source must be about $12 \mathrm{sec}$, while the first troughs at about $0.15 \mathrm{~Hz}$ observed in the case of

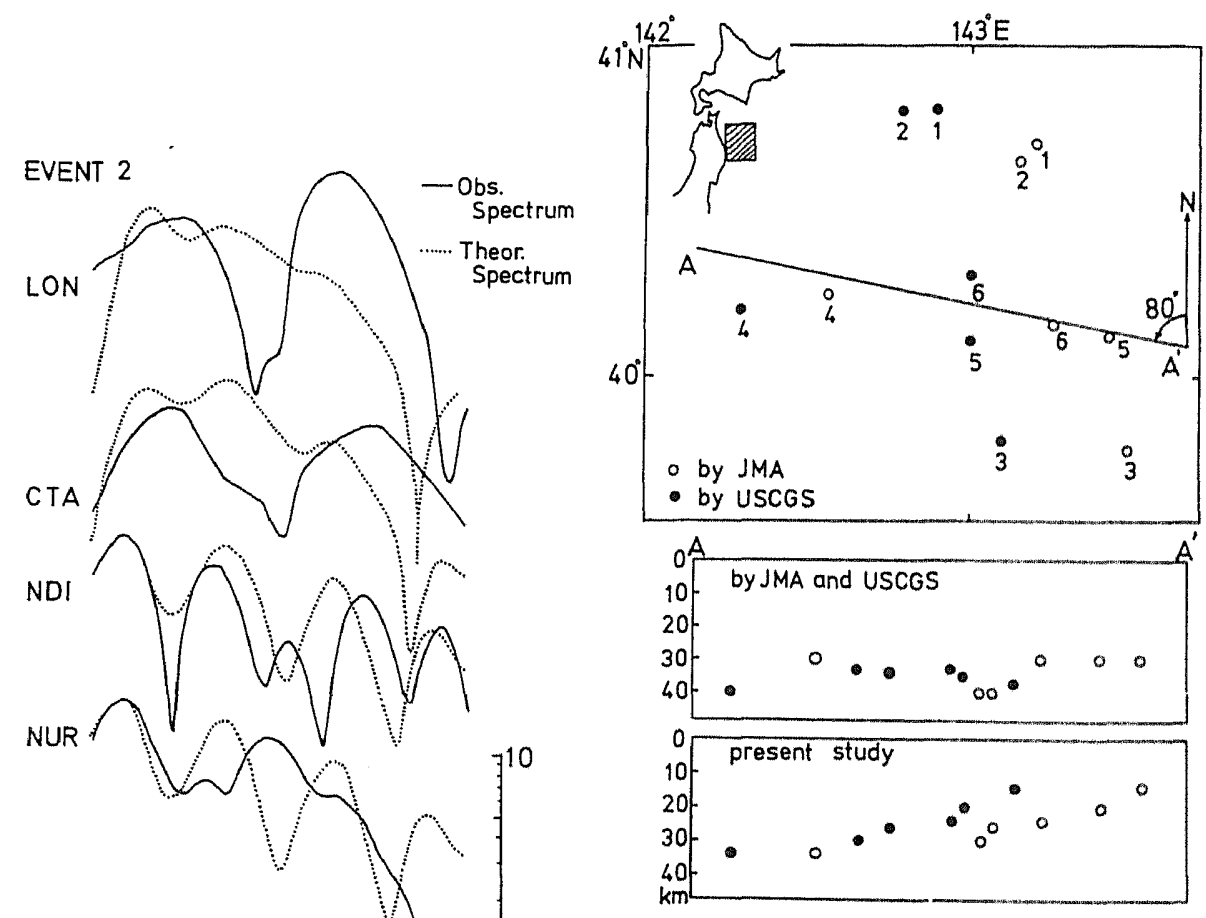

Fig. 10. Epicenter map and hypocenter distribution on the vertical section along $A-A^{\prime}$. In the result of the present study (bottom figure), open or solid circles indicate the case using the epicentral data either by JMA or by USCGS. 
Table 4. Source parameters.

$\begin{array}{ccccccccccccc}\text { Event } & \because & i & i & \begin{array}{c}a \\ (\mathrm{~km})\end{array} & \begin{array}{c}b \\ (\mathrm{~km})\end{array} & i ; & r & \begin{array}{c}v_{\mathrm{R}} \\ (\mathrm{km} / \mathrm{sec})\end{array} & \begin{array}{c}M_{0} \\ (\mathrm{dyne} \cdot \mathrm{cm})\end{array} \times \begin{array}{c}h \\ \times 10^{24}\end{array} & \begin{array}{c}\bar{u} \\ (\mathrm{~km})\end{array} & \begin{array}{c}\Delta \sigma \\ (\mathrm{cm})\end{array} & (\mathrm{bar}) \\ 1 & 88 & 18 & 106 & 19 & 9.5 & 126 & -20 & 2.9 & 50 & 26 & 39 & 22 \\ 2 & 23 & 18 & 52 & 17 & 8.5 & 43 & 9 & 3.1 & 55 & 30 & 53 & 34 \\ 3 & 53 & 14 & 85 & 20 & 10 & 70 & 15 & 2.2 & 67 & 14 & 88 & 25 \\ 4 & 55 & 24 & 77 & 12 & 6 & 58 & 19 & 2.3 & 13 & 34 & 25 & 23 \\ 5 & 51 & 14 & 83 & 11 & 5.5 & 98 & -15 & 2.7 & 7.5 & 20 & 33 & 17 \\ 6 & 76 & 16 & 103 & 10 & 5 & 90 & 13 & 2.0 & 9.0 & 24 & 47 & 27\end{array}$

$\therefore$ Dip direction; $a$, Dip angle: $\lambda$, Slip angle; $a, b$, Fault lengths in the direction of the $\xi-$ and $y$,axes; $\lambda_{i}$. Direction of the s-axis measured in the same manner as $\lambda ; \gamma$, Propagation direction of fracture front measured clockwise from the $\xi$-axis; $v_{R}$, Rupture velocity; $M_{0}$, Seismic moment: $h$. Focal depth; ir. Average displacement across the fault; $J_{r}$, Stress drop.

LON and CTA give the pulse widths of about $6.5 \mathrm{sec}$. This big difference in pulse width cannot be explained by the azimuthal effect of the propagating source with reasonable values of fault length and rupture velocity. It is further concluded that the first troughs observed at NDI and NUR come from the effect of the interference between P-and sP-waves.

The focal depths for the six events are thus determined by comparing the observed trough frequencies, which are considered to be caused by interference among $\mathrm{P}^{-}, \mathrm{pP}$ - and sP-waves, with those expected theoretically. However, since we assumed that impulsive waves were radiated from the source, the focal depths obtained here are first approximations. The focal depths are re-examined by the comparison of observed spectra and theoretical ones in which the effect of source finiteness is also included. The final results of focal depths are listed in Table 4. The re-determined focal depths are different from those given by JMA or by USCGS. It is found that the focal depth of the events becomes deeper with increasing distance of the epicenter from the trench axis. If we project the hypocenters onto the vertical section nearly perpendicular to the strike of the trench axis, the hypocenters are found to lie almost on a plane dipping slightly toward the island arc as illustrated in Fig. 10. It is suggested from the results of focal mechanism solutions in Table 3 that there exists a linear correlation between the dip angle of the fault plane and the distance of epicenter from the trench axis.

\section{Determination of Source Model}

As stated in the preceding section, the first spectral troughs at the stations from GOL to CTA cannot be regarded as those due to the effect of interference of reffected waves. Therefore, they are regarded as troughs due to the effect of source finiteness and marked by asterisk in Fig. 7. At stations 
from MUN to GDH, troughs are examined, by trial, as to whether the azimuthal difference in pulse widths derived from the trough frequencies can give reasonable values of rupture velocity and fault length or not. They will also be examined as to whether the pulse widths of the theoretical wave-forms synthesized later in this section can explain the observations. For example, the second troughs from NDI to NUR for event 5 are not marked by asterisk, because, if they are adopted, the pulse widths of theoretical waves would be too wide to explain the observations. The troughs finally adopted to determine the source parameters are marked by asterisk in Fig. 7.

Paying attention to the differences of pulse widths among stations, which can be derived from the trough frequencies, we first determine the source parameters related to the longer side of a rectangular fault model, that is, the direction of the $\xi$-axis, the fault length $(a)$ and the apparent rupture velocity $\left(v_{a}\right)$, under the following two reasonable assumptions. One is that the spectral torughs with asterisk are caused by the source finiteness in the direction of the $\xi$-axis. Since the amplitudes of $\mathrm{sP}$-waves predominate over $\mathrm{P}$ - or $\mathrm{pP}$-waves at almost all the stations, the other is that the information with regard to source finiteness is transmitted mainly by the $\mathrm{sP}$-waves.

Next, with trial values of the direction of fracture propagation and the fault length, $b$, along the $\eta$-axis, we compute the theoretical spectra and compare them with those observed, where the dislocation time function, $f(t)$ in (5), is assumed to be a unit step function. In this process, since the values of $a$ and $v_{a}$, determined from the trough frequencies as stated above, are not very accurate, they are varied a little so as to explain the observed spectra more satisfactorily. The fault length, $b$, in the direction of the $y$-axis is not well determined in general, because the effect appears in the spectrum only at a higher frequency range, where the observed spectrum is not reliable. We therefore decided to use a rough estimate of $b=a / 2$ for all the events.

The fault plane for event 4 was not distinguished from the auxiliary plane in section 4. The above procedure is carried out in both cases of two nodal planes. The agreement of the theoretical spectra with observed ones is found better when we regard the slightly dipping plane as the fault plane. The lack in the number of data for event 6 compels us to make a further assumption on the source parameter. The fault length, $a$, is taken to be $10 \mathrm{~km}$ from the empirical relation between the source dimension and the magnitude of the earthquake. The other parameters including the direction of $\xi$-axis and $v_{a}$ are determined from the comparison of theoretical spectra with observed ones by the trial and error method.

The theoretical spectra are transformed into the time domain to synthesize the theoretical seismograms. The seismic moment is determined by equalizing the amplitude of the first peak of the theoretical P-wave train 

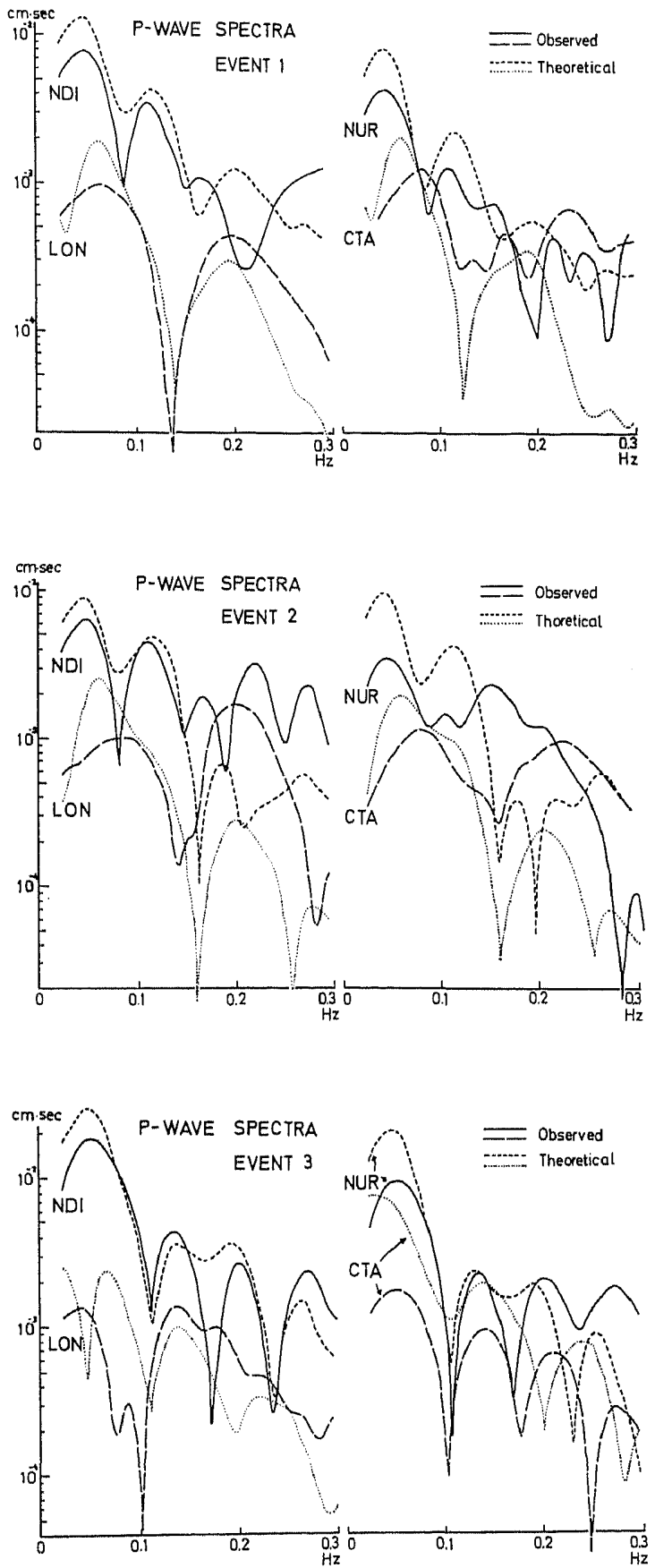

Fig. 11. Displacement spectra of the observed and theoretical P-waves for six events. 

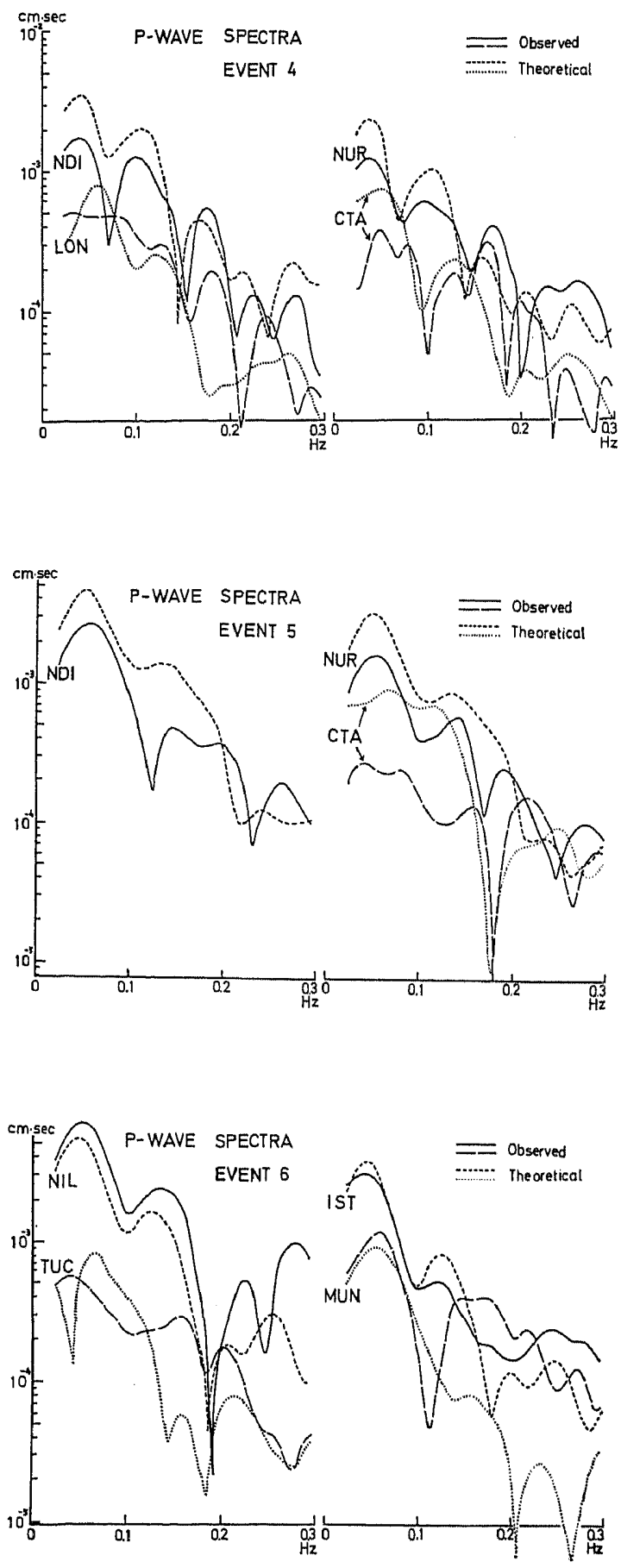

Fig. 11. continued. 

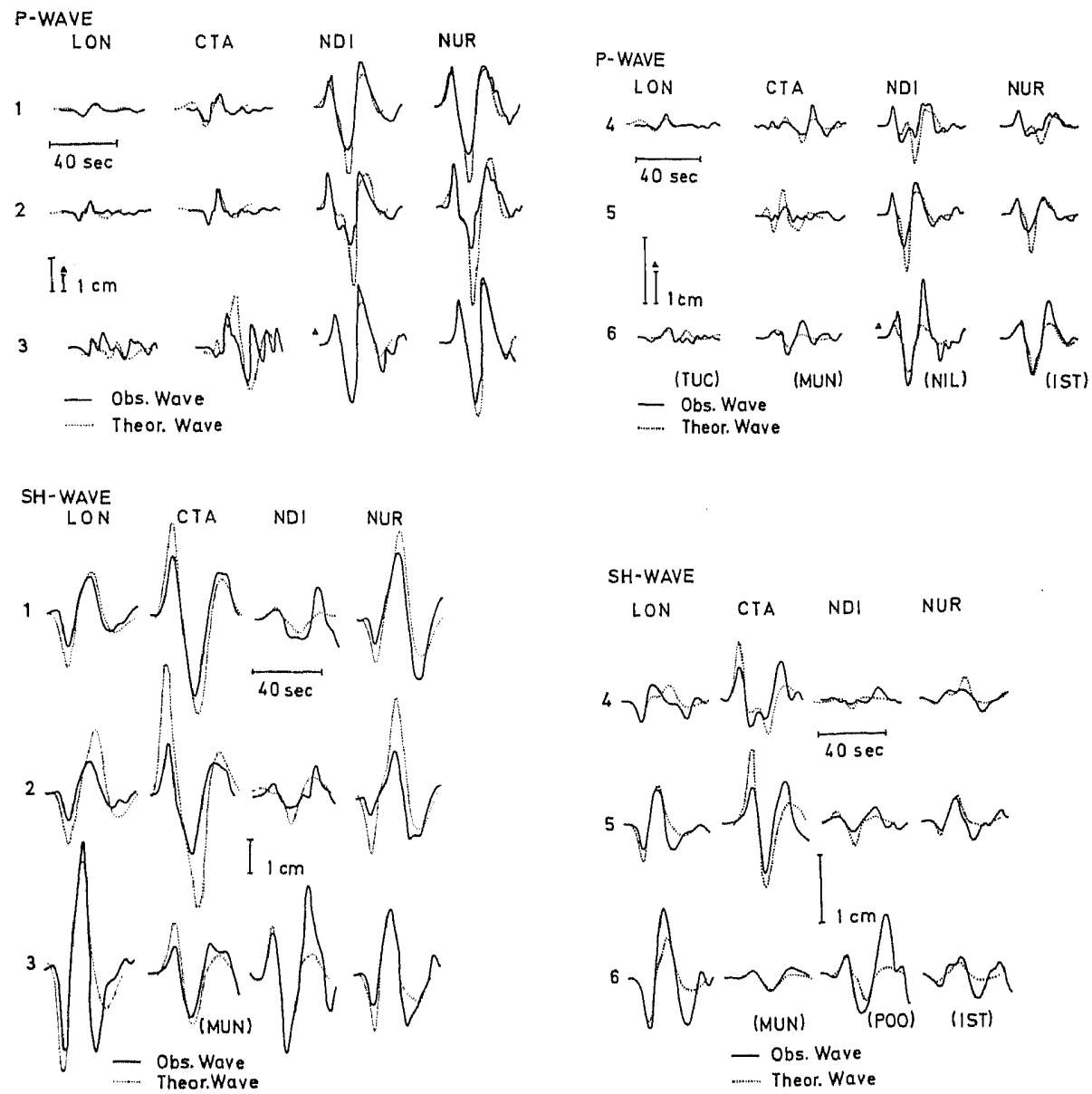

Fig. 12. Observed and theoretical P- and SH-waves for six events. The amplitude scale marked by triangle should be applied to the wave-forms with triangle.

with that observed. Since the amplitude corrections for the radiation pattern are not reliable for stations located near the P-nodal plane, data from these stations are not used to estimate the seismic moment.

It is found for all the events that the fracture propagates approximately in the motion direction of the foot wall block, that is, the direction of $z$-axis in Fig. 8. Figures 11 and 12 show theoretical spectra and synthesized P-and SH-wave-forms in comparison with observed ones. The source parameters thus determined are listed in Table 4. The average dislocation, $\bar{u}$, on the fault plane and the stress drop, $\Delta \sigma$, are also given in Table 4 for the purpose of reference, where it must be kept in mind that these values depend critically on the poor estimate of the shorter fault length, $b$. 


\section{Discussions}

KANAMORI (1971) investigated the focal mechanisms of the Tokachi-Oki earthquake of 1968 and its aftershocks by analyzing the observed data of surface waves. He found that the focal mechanism solution of the largest aftershock is opposite to that of the main shock, that is, the maximum and the minimum compressional axes of these shocks change places with each other. He has attributed this to complex interactions among three plates (the northeastern Japan plate, the Hokkaido plate and the Pacific plate) at the junction of the Japan and the Kurile trenches.

In the present study, the focal mechanism solutions of events 1 and 2 were found to be of the thrust faulting type, which are usually found at the subduction zone of the oceanic plate beneath the island arc. Although these earthquakes occurred near the junction prior to the occurrence of the Tokachi-Oki earthquake, the mechanism solutions show no indications for such a complex interaction of the plates as proposed by KANAMORI (1971).

Ben-Menahem and Toksöz $(1962,1963 \mathrm{a}, \mathrm{b})$ estimated the rupture velocities for large shallow earthquakes, the Mongolian of 1957, the Kamchatka of 1952, and the Alaska earthquake of 1958, at values ranging from 3.0 to $3.5 \mathrm{~km} / \mathrm{sec}$. HrRASAWA (1965) obtaind the rupture velocity of $2.0 \mathrm{~km} / \mathrm{sec}$ for the Niigata earthquake. Bollinger (1970) estimated the rupture velocity at $3.1 \mathrm{~km} / \mathrm{sec}$ for the Kyushu earthquake of 1963 . The rupture velocities for the six events estimated in the present study range from 2.0 to $3.1 \mathrm{~km} / \mathrm{sec}$. The values seem to be reasonable for rupture velocities of shallow earthquakes with reference to the results obtained in the previous studies.

The result in section 8 shows that the fracture was propagated in the motion direction of the foot wall block for each event. This propagation direction of fracture suggests that the moving edge dislocation was predominant during faulting. On the other hand, HIRASAwa (1965) modeled the Niigata earthquake by a bilateral fracture which was propagated in the horizontal direction. Since the mechanism solution of the earthquake was nearly pure dip-slip with the dip angle of $45^{\circ}$, the fracture front was represented by a line segment of the screw dislocation type.

KANAMORI (1970a) analyzed the long-period surface waves from the Kurile Islands earthquake of 1963 and found that the mechanism solution was a reverse dip-slip with a dip angle of $22^{\circ}$. For the direction of the fracture propagation he adopted the direction of strike of the fault plane which explained the observation reasonably well. KANAMORI (1970b) also found for the Alaska earthquake of 1964 that the mechanism solution was a reverse dip-slip with a dip angle of $20^{\circ}$ and the angle between the direction of the fracture propagation and the motion direction of the foot wall block was about 
$130^{\circ}$. In the case of the Tokachi-Oki earthquake, KANAMORI (1971) suggested that the fracture was propagated in the direction of strike of the fault plane.

The present result for the direction of fracture propagation, which does not agree with those of previous studies stated above, must be related with the geometry of rectangular slip surface relative to the strike of the fault plane; the fault length in the strike direction being shorter than that in the dip direction of the fault plane. It is suggested that earthquakes of moderate size differ both in the fault geometry relative to the strike of the fault plane and in the direction of fracture propagation from large shallow earthquakes in the subduction zone.

Shortly after the arrival of the initial $P$ phase, a phase which cannot be identified with one of the known phases in the travel time table is clearly seen in the seismograms of NDI and NUR for event 1 (see Fig. 3). This phase (hereafter called $P_{2}$ phase) is not found in seismograms of event 2 which occurred at almost the same location as event 1 . Although the $P_{2}$ phase has been neglected in our analysis of the preceding sections, it may be interpreted as the initial phase radiated by the second shock that took place near the first shock with a small time delay. Let us try to find the hypocenter and the origin time of the second shock relative to those of the first shock. Unfortunately, the distribution of observation stations is so biased on the focal sphere that the hypocenter cannot be determined without some constraint. We assume, therefore, that the second shock occurred on the fault plane of the first shock. The hypocenter of the second shock is determined on the fault plane near the direction of fracture propagation of the first shock with a distance of $17 \mathrm{~km}$ and a time lag of $4.4 \mathrm{sec}$. Moreover, if we assume that the second shock was triggered by the arrival of some stress disturbance generated by the first shock, we can determine the average velocity of the disturbance as $3.9 \mathrm{~km} / \mathrm{sec}$. This propagation velocity is rather high in comparison with the propagation velocity of fracture front, $2.9 \mathrm{~km} / \mathrm{sec}$, obtained in the preceding section.

\section{Conclusion}

Six shallow earthquakes that occurred in the Sanriku-Oki region have been studied by using the long period P-and S-waves. The source mechanisms of the earthquakes resemble one another so far as we have examined in this study. The main results obtained are summarized as follows:

1) The focal mecanism solutions obtained by S-wave data satisfactorily explain the observed amplitudes of initial motion of $\mathrm{P}$-waves.

2) The focal mechanism solutions for all six events are of the thrust faulting type. 
3) The fault plane for each event found from the hypocenter distribution of aftershocks is the nodal plane slightly dipping toward the island arc. The larger the distance between the epicenter of earthquake and the trench axis is, the bigger the dip angle of the fault plane becomes.

4) The motion directions of the foot wall blocks for the six events are in the range from $\mathrm{N} 58^{\circ} \mathrm{W}$ to $\mathrm{N} 72^{\circ} \mathrm{W}$ on the horizontal plane in agreement with the motion direction of the Pacific plate relative to the Eurasia plate.

5) The focal depths re-determined by the use of depth phases differ from those given either by JMA or by USCGS, and the hypocenters lie almost on a plane slightly dipping toward the island arc. It turns out that the earthquakes studied are all typical inter-plate earthquakes.

6) The faulting processes of the six events are found to be described by a unilateral bidirectional fault model from the comparison of the theoretical seismic spectra with those observed.

7) For each event, the fracture front on the fault plane seems to propagate in the motion direction of the foot wall block.

8) The velocities of the fracture propagation range from 2.0 to $3.1 \mathrm{~km} / \mathrm{sec}$.

The authors wish to express their thanks to Prof. Z. Suzuki and Prof. A. Takagi of the Tôhoku University for their kind guidance and encouragement. The authors are indebted to Dr. K. Yamamoto, Dr. S. Horiuchi and Dr. J. Koyama of the Tôhoku University and Dr. T. Sato of the Hirosaki University for their suggestions and helpful discussions.

\section{REFERENCES}

Ben-Menahem, A. and M. N. Toksöz, Source mechanism from spectra of long-period seismic surface waves. 1. The Mongorian earthquake of December 4, 1957, J. Geophys. Res., 67, 1943-1955, 1962.

Ben-Menahem, A. and M. N. Toksöz, Source mechanism from spectrums of long-period seismic surface waves. 2. The Kamchatka earthquake of November 4, 1952, J. Geophys. Res., 68, 5207-5222, 1963a.

Ben-Menahem, A. and M. N. Toksöz, Source mechanism from spectrums of long-period seismic surface waves. 3. The Alaska earthquake of July 10, 1958, Bull. Seismol. Soc. Am., 53, 905-919, 1963b.

Ben-Menahem, A., S. W. Smith, and T. L. Teng, A procedure for source studies from spectrums of long period seismic body waves, Bull. Seismol. Soc. Am., 55, 203 235, 1965.

Blackman, R. B. and J. W. Tukey, The Measurement of Power Spectra, Dover, New York, 1958.

Bollinger, G. A., Determination of earthquake fault parameters from long-period $P$ waves, J. Geophys. Res., 73, 785-807, 1968.

Bollinger, G. A., Fault length and fracture velocity for the Kyushu, Japan, earthquake of October 3, 1963, J. Geophys. Res., 75, 955-964, 1970.

FUKAo, Y., Focal process of a deep focus earthquake as deduced from long period $\mathbf{P}$ and $\mathbf{S}$ waves, Bull. Earthq. Res. Inst. Univ. Tokyo, 48, 707-727, 1970.

Haskell, N. A., Crustal reflection of plane SH waves, J. Geophys. Res., 65, 4147 4150, 1960. 
Hirasawa, T., Source mechanism of the Niigata earthquake of June 16, 1964, as derived from body waves, J. Phys. Earth, 13, 35-66, 1965.

Hirasawa, T., A least squares method for the focal mechanism determination from $\mathrm{S}$ wave data. Part I, Part II. Applied examples and statistical discussions, Bull. Earthq. Res. Inst. Univ. Tokyo, 44, 901-918, 919--938, 1966.

Hirasawa, T. and W. Stauder, S. J., On the seismic body waves from a finite moving source, Bull. Seismol. Soc. Am., 55, 237-262, 1965.

Honds, H., Earthquake mechanism and seismic waves, Geophysical Notes, Univ. Tokyo, 15 (Supplement), 1-97, 1962.

IsACKS, B., J. Oliver, and L. R. Sykers, Seismology and the new global tectonics, J. Geophys. Res., 73, 5855-5899, 1968.

KANAmori, H., Synthesis of long-period surface waves and its application to earthquake source studies -Kurile Islands earthquake of October 13, 1963, J. Geophys. Res., 75, $50115027,1970 \mathrm{a}$.

Kanamori, H., The Alaska earthquake of 1964: Radiation of long-period surface waves and source mechanism, J. Geophys. Res., 75, 5029-5040, 1970 b.

Kanamori, H., Focal mechanism of the Tokachi-Oki earthquake of May 16, 1968: Contortion of the lithosphere at a junction of two trenches, Tectonophysics., 12, 1-13, 1971.

KHATTRI, K. N., Determination of earthquake fault plane, fault area, and rupture velocity from the spectra of long period P waves and the amplitude of SH waves, Bull. Seismol. Soc. Am., 59, 615 630, 1969.

Kusunose, K. and T. HrRASAwa, Characteristics of aftershock occurrence in the case of the Southeastern Akita Earthquake of 1970, Zisin, 30, 295-306, 1977.

Mikumo, T., Long-period $P$ waveforms and the source mechanism of intermediate earthquakes, J. Phys. Earth, 17, 169-192, 1969.

Miкumo, T., Source process of deep and intermediate earthquakes as inferred from longperiod $\mathrm{P}$ and $\mathrm{S}$ waveforms. 1. Intermediate-depth earthquakes in the southwest Pacific region, J. Phys. Earth, 19, 1-19, 1971.

SASATANI, T., Re-examination of the source mechanism of the earthquake off the east coast of Aomori Prefecture, Zisin, 26, 67-76, 1973.

Staudik, W., Mechanism of the Rat Island earthquake sequence of February 4, 1965, with relation to island ares and sea-floor spreading, J. Geophys. Res., 73, 3847-3858, 1968.

TI:NG, T. and A. BEN-MINAHIM, Mechanism of deepearthquakes from spectrums of isolated body-wave signals. 1. The Banda Sea earthquake of March 21, 1964, J. Geophys. Res., 70, $5157.5170,1965$. 